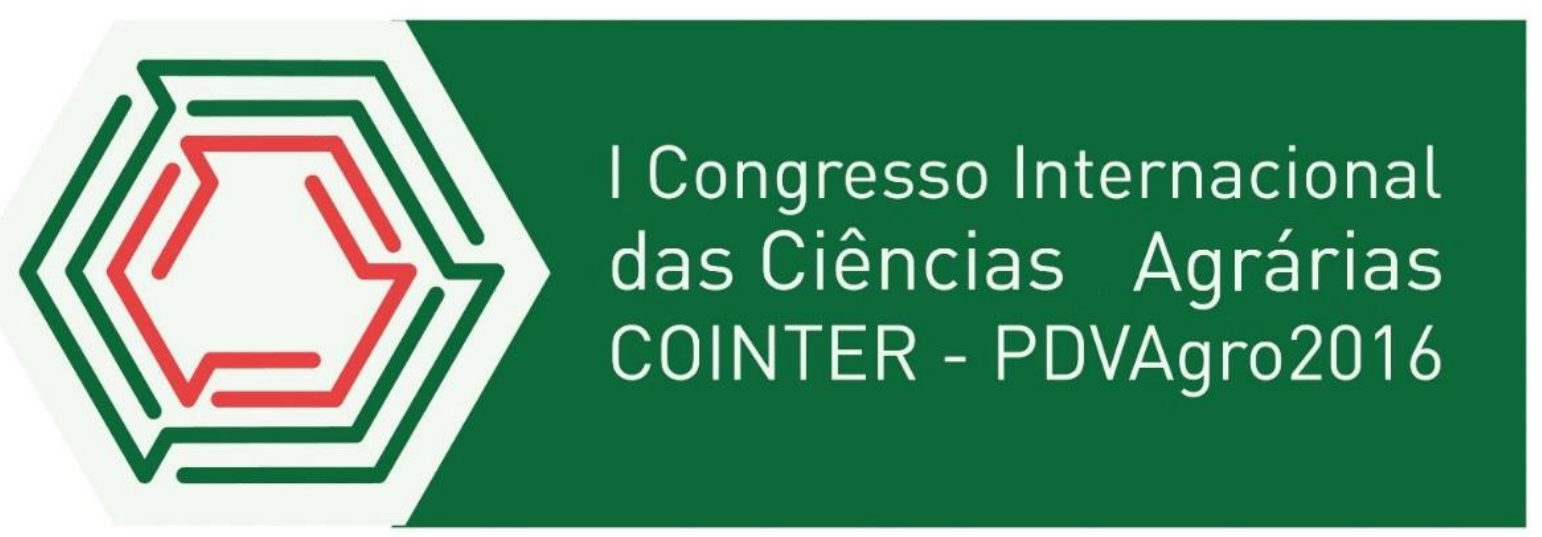

\title{
INFLUÊNCIA DA COBERTURA MORTA SOB O USO DE ÁGUA SALINA NA PRODUÇÃO DE MUDAS DE GLIRICÍDIA
}

\author{
Apresentação: Comunicação Oral \\ Sebastiana Joelma de Azevedo Santos¹; José Wellington de Medeiros Estrela²; Frederico \\ Campos Pereira ${ }^{3}$
}

\begin{abstract}
Resumo
A utilização de resíduos orgânicos como substrato é uma alternativa promissora no cultivo de plantas forrageiras, reduzindo os custos e o acúmulo desses materiais no ambiente, bem como, o uso da cobertura morta apresenta relevante importância para regiões árida e semiárida do Brasil atribuindo fatores químicos, físicos e biológicos ao solo. O objetivo do trabalho foi avaliar o desenvolvimento de plantas de gliricídia (Gliricidia sepium) irrigadas com água não salina e salina utilizando-se substratos residuários para o uso da cobertura morta. $\mathrm{O}$ delineamento experimental foi o inteiramente casualizado, em arranjo fatorial $2^{3} \mathrm{com}$ dois níveis de condutividade elétrica da água para irrigação $\left(0,2 \mathrm{dS} \mathrm{m} \mathrm{m}^{-1}\right.$ e $\left.7,5 \mathrm{dS} \mathrm{m}^{-1}\right)$, dois substratos (pó de café e pó de serra) e uso de cobertura morta em quatro repetições. Após três meses foi avaliado a altura da parte aérea, número de folhas e diâmetro caulinar. O método estatístico utilizado foi o comparativo descritivo compondo-se as médias. Para a variável altura, o substrato contendo pó de café irrigado com água de baixa salinidade, concomitamente, com o uso da cobertura, apresentou melhores resultados quando comparouse com o substrato contendo pó de serra. Na irrigação com água salina, a adição da cobertura morta, não apresentou resultados satisfatórios causando uma redução nas médias, resultando em maior período para desenvolvimento das plantas jovens. Para todas as variáveis a utilização da cobertura morta quando irrigou-se com água de baixa salinidade e uso do substrato residuário orgânico contendo pó de café propiciou uma maior evolução. A elevação da salinidade da água de irrigação inibiu o desenvolvimento das plantas.
\end{abstract}

Palavras-Chave: Cobertura vegetal, estresse salino, Gliricidia sepium, resíduos orgânicos.

\section{Introdução}

A gliricídia (Gliricidia sepium (Jacq.) Steud) é uma espécie dicotiledônea, pertencente à família Fabaceae (leguminosae), subfamília Papilionoideae, sendo caracterizada como uma

1 Pós-graduanda em Gestão dos Recursos Ambientais do Semiárido, IFPB, joelmaifpbpicuiy@gmail.com

${ }^{2}$ Graduando em Agroecologia, IFPB, wellingtonestrela18@hotmail.com

${ }^{3}$ Professor do Curso de Agroecologia, IFPB, fredcampos2000@yahoo.com.br 
planta perene, arbórea de porte médio, com crescimento rápido e enraizamento profundo, o que lhe confere notável tolerância à seca. É considerada como espécie utilizada para forragem, reflorestamento, adubação verde, cercas vivas, entre outros. Desenvolve-se melhor em condições quentes e úmidas, tendo o seu crescimento limitado por baixas temperaturas, podendo, entretanto, tolerar prolongados períodos de seca, ainda que com queda de folhas dos ramos mais velhos. Não necessita de solos férteis, embora exiba melhor desempenho naqueles de alta fertilidade e profundos o suficiente para um bom enraizamento, fator determinante da maior ou menor produção e manutenção de folhagem verde no período seco (CARVALHO FILHO et al., 1997).

O uso da cobertura morta apresenta relevante importância para regiões árida e semiárida do Brasil atribuindo fatores químicos, físicos e biológicos ao solo, com reflexos na redução da perda de água por evaporação, por reduzir as oscilações térmicas, criando condições favoráveis ao crescimento radicular e reduzindo o aparecimento de plantas espontâneas. A cobertura vegetal mantém o solo mais úmido devido ao efeito da não exposição à ação do vento e à radiação solar, e a proteção edáfica proporciona uma economia hídrica comparada às plantas cultivadas em solo sem cobertura.

A utilização de resíduos orgânicos como substrato é uma alternativa promissora no cultivo de plantas forrageiras, reduzindo os custos e o acúmulo desses materiais no ambiente. O cultivo de plantas produzidas com a utilização de adubos orgânicos tem crescido nos últimos anos, em função dos elevados custos dos adubos minerais e dos agentes nocivos dos produtos químicos nos lençóis subterrâneos, rios, lagos, flora e fauna local (SANTOS et al., 2001). Além disso, adubos orgânicos residuários, como o pó de café e pó de serra, influem nas propriedades físico-químicos e biológicos do solo ou substrato. Entretanto, o agricultor pode produzir seu próprio substrato a custo muito baixo, desde que tenha acesso às informações técnicas adequadas (FILGUEIRA, 2000).

Em relação à salinidade, esta é um dos mais sérios problemas enfrentados na agricultura irrigada, porém, os efeitos sobre o crescimento das plantas são consequências de fatores osmóticos e iônicos. A salinidade é um dos fatores que mais limitam o crescimento e a nutrição mineral de plantas em regiões com baixa disponibilidade hídrica, devido à redução do potencial osmótico no ambiente radicular (DASGAN et al., 2002).

Contudo, a necessidade de se avaliar espécies tolerante ou resistente aos sais levou a realização desse experimento. Com isso, o presente trabalho objetivou avaliar o 
desenvolvimento de plantas de Gliricidia sepium irrigadas com água salina e não salina utilizando-se substratos residuários e uso de cobertura morta.

\section{Fundamentação Teórica}

O uso de cobertura morta, como proteção do solo, diminui a evaporação da água adicionada durante a irrigação, evitando a precipitação de sais na zona radicular. Segundo Stamets \& Chilton (2003), essa camada protege o substrato colonizado contra a perda de água, favorece a formação de microclima úmido, serve como reservatório de água para a cultura em crescimento e favorece o desenvolvimento de microrganismos benéficos à frutificação. A cobertura morta pode prover nutrientes às plantas conforme Cadavid et al. (2008), promove o crescimento do sistema radicular na camada superficial e reduz as flutuações de temperatura do solo (GILL et al., 2006). Depois de incorporada ao solo, essa proteção viabiliza o aumento da quantidade de água disponível à planta (STEWART, 2004).

Nos solos afetados por sais, o Na é o que causa mais problemas, podendo interferir no crescimento das plantas, segundo Kashem et al. (2000), e na distribuição de nutrientes nas suas partes (VIANA et al., 2001). Algumas espécies vegetais apresentam rendimentos favoráveis, inclusive em condições de cultivo em alta salinidade e sodicidade, muito embora outras sejam mais sensíveis. A gliricídia destaca-se por sua tolerância aos sais e têm o $\mathrm{Cl}^{-}$ como macronutriente (UEXKULL, 2002). Segundo Ayers \& Westcot (2001), essa diferença associa-se à melhor capacidade de adaptação osmótica de algumas espécies, sendo estas capazes de absorver e acumular íons, utilizando-os na síntese de compostos orgânicos, além de absorverem água quando submetidas a baixos potenciais osmóticos.

A escolha da cultura a ser irrigada deve levar em consideração, principalmente, sua adaptação ao clima e sua tolerância à salinidade da água e do solo. Segundo Guillen-Portal et al. (2009), uma das culturas que se adaptam bem às condições de alta insolação e à temperatura de morna a quente, típicas das regiões áridas e semi-áridas, é o gênero Gliricidia sepium. Essa cultura se adapta, também, a altitudes que vão desde o nível do mar até $3.500 \mathrm{~m}$ (TEIXEIRA et al., 2003). Todavia, o excesso de sais pode interferir na área foliar (Makus, 2003) e na produção de biomassa (PARDOSSI et al., 1999; ROMERO-ARANDA et al., 2001).

Por ser a gliricídia uma cultura de alto teor protéico, variando de 12 a $17 \%$, com perfil de aminoácido bem distribuído, incluindo alta quantidade de lisina (MYERS, 2006), ela desponta como uma espécie capaz de diversificar a produção de forragem, na região do Nordeste brasileiro, principalmente em períodos de estiagem. 


\section{Metodologia}

A pesquisa foi conduzida no Setor de Produção Vegetal de Agroecologia do Instituto Federal de Educação, Ciência e Tecnologia da Paraíba, Campus Picuí. O experimento foi instalado em delineamento inteiramente casualizado, com quatro repetições, em arranjo fatorial $2 \times 2 \times 2$, correspondente a dois níveis de condutividade elétrica da água de irrigação $\left(0,5\right.$ e $\left.7,5 \mathrm{dS} \mathrm{m}^{-1}\right)$, no solo sem e com cobertura morta, com três plantas por unidade experimental, totalizando 96 plantas. Os tratamentos foram iniciados no dia do plantio das sementes.

O material testado constou de mudas de gliricídia, produzidas em sacos de polietileno com dois substratos. O substrato 1 consistiu de uma mistura de Neossolo flúvico ou aluvião, esterco bovino e parte de material residuário doméstico (pó de café), na proporção 2:1:1/2. O substrato 2 consistiu de uma mistura de Neossolo flúvico ou aluvião, esterco bovino e parte de material residuário de marcenaria (pó de serra), na proporção 2:1:1/2

As águas de irrigação foram oriundas do Sítio Várzea Verde, no município de Frei Martinho-PB, baixa salinidade $\left(\mathrm{CEa}=0,2 \mathrm{dS} \mathrm{m}^{-1}\right)$ e a salina $\left(\mathrm{CEa}=7,5 \mathrm{dS} \mathrm{m}^{-1}\right)$, no açude Várzea Grande que abastece o município e região, localizado no município de Picuí-PB. A cobertura morta foi coletada em uma marcenaria da cidade de Picuí-PB, oriunda de material residuário proveniente de partículas maiores quando trabalhada a madeira, com auxílio de máquinas, como também o pó de serra coletado para o substrato utilizado foi o de partículas minúsculas. Foi semeadas duas sementes de gliricídia por tratamento, com posterior desbaste aos 20 dias após a germinação.

As irrigações foram efetuadas com frequência de três dias, com dotação hídrica mantenedora do substrato em capacidade de campo. As variáveis analisadas neste trabalho constam de número de folhas, altura $(\mathrm{cm})$ e diâmetro caulinar $(\mathrm{mm})$ após 90 dias de instalado o experimento. A altura das plantas foi mensurada com uma régua graduada, do coleto até o ponto de inserção das últimas folhas. Com o auxílio de um paquímetro foi mensurado os diâmetros caulinares à altura da base dos coletos. O método estatístico utilizado foi o comparativo descritivo compondo-se as médias.

\section{Resultados e Discussão}

Observou-se, no decorrer deste experimento, durante três meses, que o substrato obtido a partir de resíduo orgânico pó de café, quando se utilizou a água para irrigação de baixa salinidade $\left(0,2 \mathrm{dS} \mathrm{m}^{-1}\right)$, apresentou um melhor desempenho para as plantas de 
Gliricidia sepium relacionadas ao seu número de folhas, quando comparadas com o substrato contendo pó de serra, independentemente da adição da cobertura morta. O aumento da salinidade da água de irrigação $\left(7,5 \mathrm{dS} \mathrm{m}^{-1}\right)$ inibiu o aparecimento de novas folhas, retardando o desenvolvimento da planta. O substrato que contém o pó de serra, na mesma condição de acréscimo da salinidade da água de irrigação, e com uso da cobertura vegetal houve um decréscimo significante em sua média. Isso se explica pelo fato do uso da cobertura favorecer a umidade e os sais contidos na água de irrigação é um fator inibidor do desenvolvimento dessas plantas havendo redução no número de folhas, conforme indicado na figura 1.

Figura 1. Número de folhas de plantas de Gliricidia sepium influenciadas pelo substrato e uso de água salina em solo com e sem cobertura. Fonte: Própria.

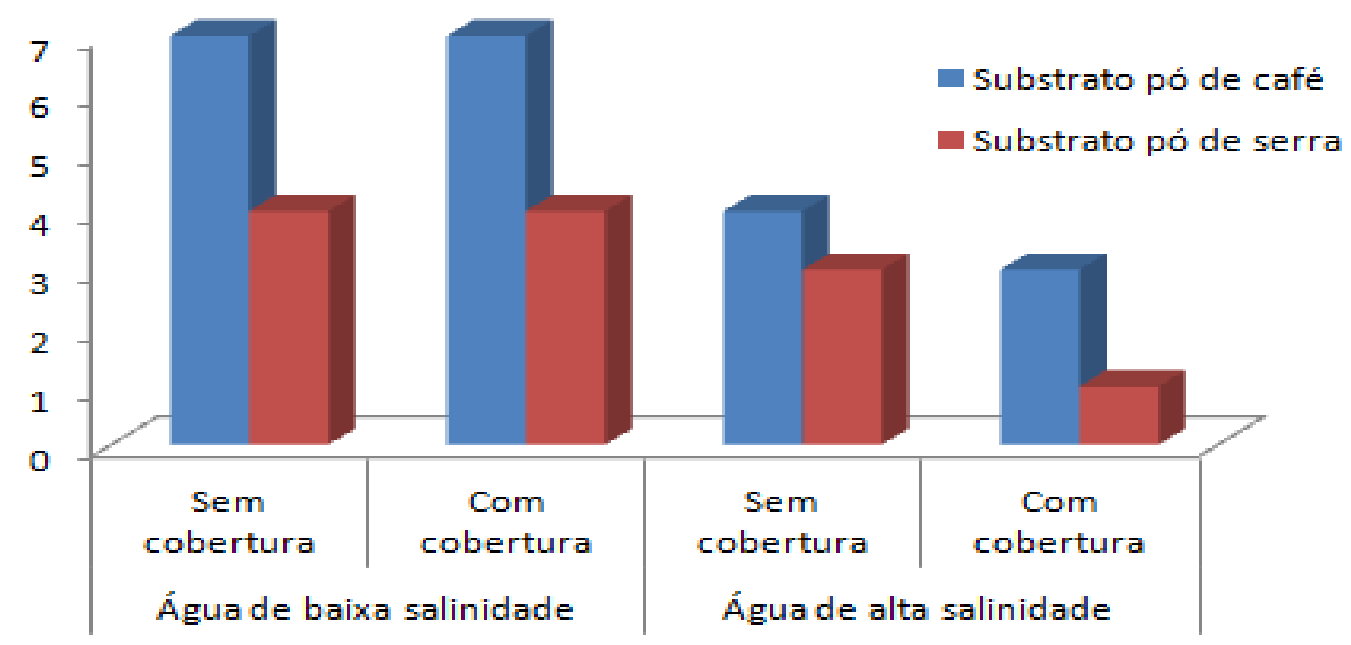

Esses efeitos negativos nas plantas estão associados ao desbalanço nutricional em decorrência da redução da disponibilidade de $\mathrm{K}^{+}, \mathrm{Ca}^{2+}$ e $\mathrm{Mg}^{2+}$ pela alta concentração de $\mathrm{Na}^{+}$ no solo; à toxidez por elevado teor de íons como o $\mathrm{Na}^{+}, \mathrm{Cl}^{-1}$ ou SO $4^{2-}$ nas plantas, com prejuízos nas funções dos sistemas enzimáticos e síntese proteica, interferindo na estrutura e na função de enzimas ou na função do $\mathrm{K}^{+}$e ao efeito osmótico, restringindo a absorção de água pelas raízes, sob baixo potencial hídrico da solução do solo, resultando em diminuição na turgescência celular, abertura estomática, assimilação líquida de $\mathrm{CO}_{2}$, declínio da eficiência fotossintética, comprometendo o crescimento, desenvolvimento e o potencial produtivo das culturas (LACERDA et al., 2001; EPSTEIN \& BLOOM, 2006).

O substrato contendo pó de café irrigado com água de baixa salinidade, concomitamente, com o uso da cobertura, apresentou melhores resultados em altura para as plantas de gliricidia ao comparar-se com o substrato contendo pó de serra (Figura 2). Para o 
substrato contendo pó de serra e irrigação com água salina, a adição da cobertura vegetal, não apresentou resultados satisfatórios causando uma redução das plantas em altura, resultando em maior período para o seu desenvolvimento. Com isso, evidencia-se o efeito negativo do insumo sobre o crescimento inicial das plantas com o aumento do nível de salinidade da água de irrigação. E, também, porque a cobertura utilizada é oriunda de resíduos de marcenaria, ficando, assim, o substrato com uma maior quantidade desse resíduo disponível para a planta.

Figura 2. Altura de plantas de Gliricidia sepium influenciadas pelo substrato e uso de água salina em solo com e sem cobertura. Fonte: Própria.

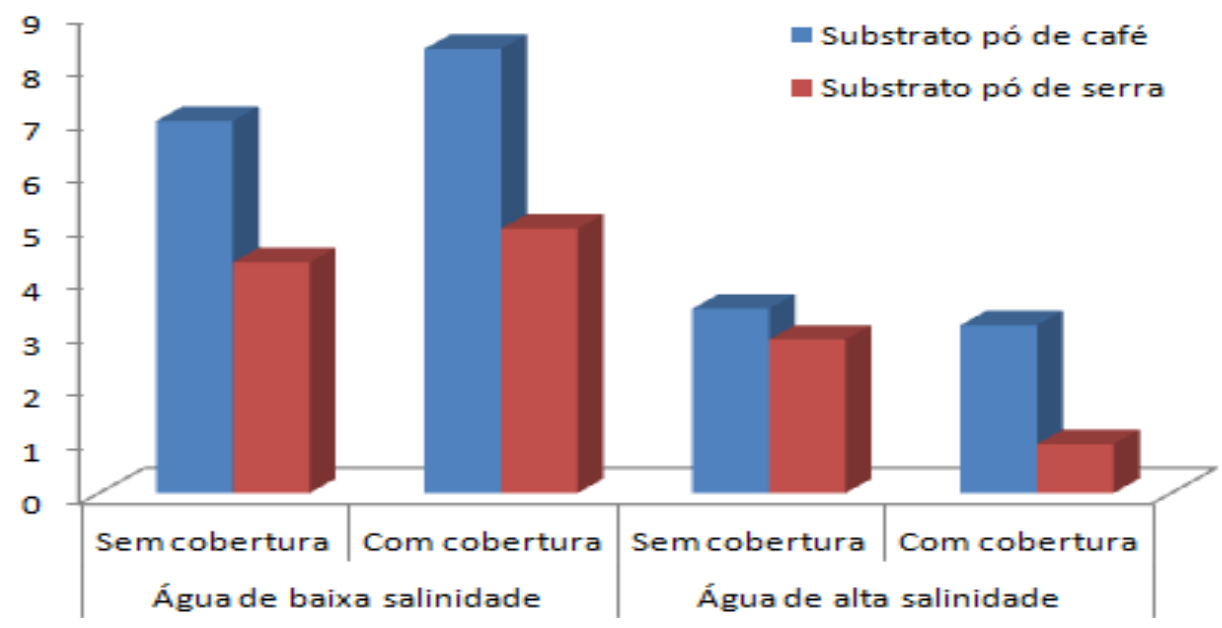

Esses resultados são concordantes com os obtidos por Campos et al. (2009), nos quais a adição desse insumo aumentou o tempo de poda da haste principal do maracujazeiro amarelo, mas, inferiores à variação observada por Cavalcante et al. (2006) após utilizarem o mesmo tipo de insumo.

$\mathrm{Na}$ análise da variável diâmetro caulinar, observei que a adição da cobertura vegetal no substrato contento pó de café estimulou o seu desenvolvimento nas duas condições de uso da água de irrigação (Figura 3). No tratamento com água não salina, a interação com a proteção orgânica possibilitou uma média de 0,5 no diâmetro, ao passo que com água de 7,5 $\mathrm{dS} \mathrm{m}^{-1}$ foi de 0,33 . Evidenciou-se a mesma tendência de efeitos positivos do pó de café observada para tratamentos sem o uso da cobertura do solo.

Segundo Assis et al, 2011 ao realizar trabalhos com casca de café para o cultivo de orquídeas este apresentou resultado satisfatório quando comparados com os demais substratos. O pó de café atrai fungos que são essenciais para as plantas atuando ma microfauna do solo de forma benéfica, além de ser uma fonte de matéria orgânica provida de nutrientes. Há carência de trabalhos científicos na literatura sobre a utilização deste substrato, 
porém sendo necessário o desenvolvimento de outros trabalhos.

Constatou-se, no tratamento contendo pó de serra, comportamento invertido com relação ao uso da cobertura (Figura 3). No tratamento sem cobertura morta, o substrato estimulou em cerca de 0,26 a média do diâmetro caulinar, reduzindo para 0,17 o seu diâmetro com uso cobertura.

Figura 3. Diâmetro caulinar de plantas de Gliricidia sepium influenciadas pelo substrato e uso de água salina em solo com e sem cobertura. Fonte:Própria.

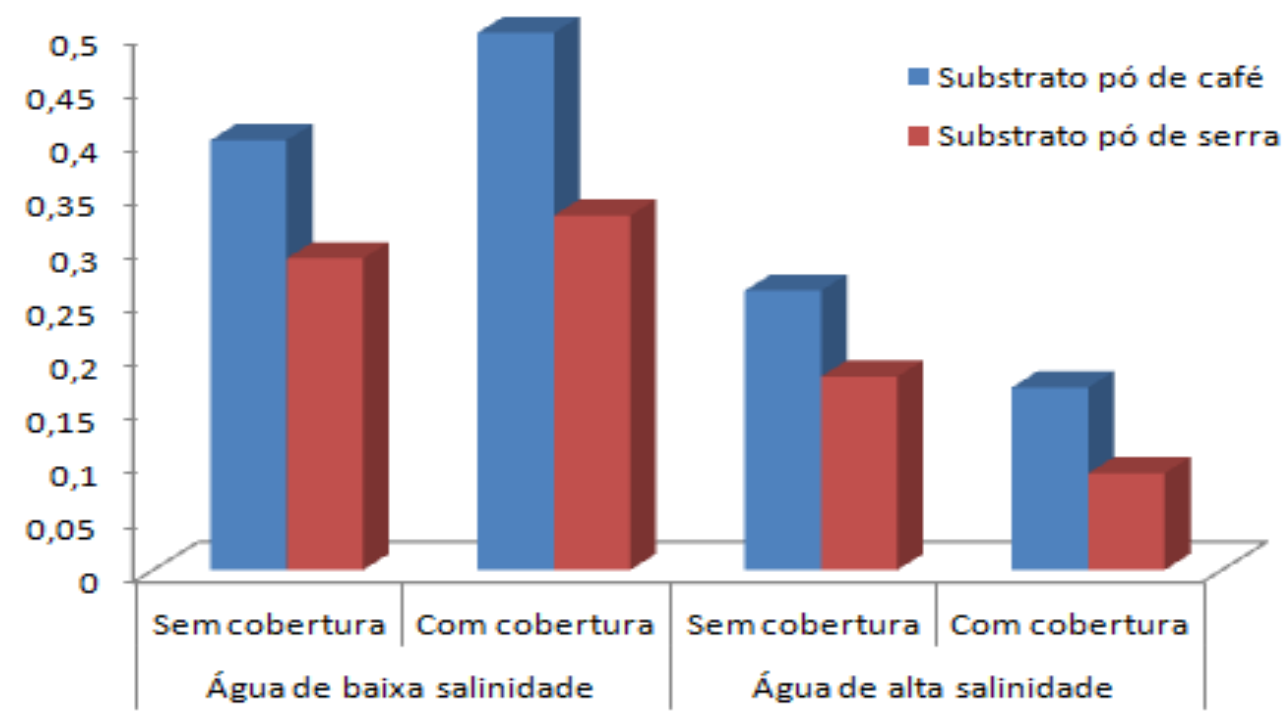

Essa mesma tendência foi observada por Campos et al. (2008), ao realizar experimento com pimentão, ressaltando a hipótese de que a cobertura vegetal possibilita uma maior atividade microbiana no ambiente edáfico, resultando em maior competição nutricional, com reflexos negativos no crescimento das plantas, como também para o diâmetro caulinar.

\section{Conclusões}

A cobertura morta favoreceu o desenvolvimento das plantas em substrato contendo pó de café até mesmo com o aumento da salinidade da água de irrigação.

O uso da cobertura morta residuária oriunda de pó de serragem não surtiu efeitos significativos quando se utilizou o substrato contento pó de serra independentemente da utilização da água de irrigação, em todas as variáveis.

O substrato oriundo da matéria orgânica residuária doméstica pó de café, surtiu efeitos relevantes em mudas de gliricidia, quando comparado com o substrato de origem residuária de marcenaria pó de serra, sendo assim, recomendado para a produção de mudas dessa planta 
forrageira, por ser facilmente disponível ao agricultor à baixo, ou sem nenhum, custo.

\section{Agradecimentos}

Ao IFPB - Instituto Federal de Educação, Ciência e Tecnologia da Paraíba, Campus Picuí.

Ao NEA - Núcleo de Estudos em Agroecologia.

Ao GPES - Grupo Paraibano de Estudos Socioambientais.

\section{Referências}

ASSIS, A. M. et al. Cultivo de orquídea em substratos à base de casca de café. Bragantia, Campinas, SP, v. 70, n. 3, p.544-549, 2011.

AYERS, R. S.; WESTCOT, D. W. A qualidade da água na agricultura. Campina Grande, Universidade Federal da Paraíba, 2001. 218p.

CADAVID, L. F.; EL-SHARKAWY, M. A.; ACOSTA, A.; SANCHES, T. Long-term effects of mulch, fertilization and tillage on cassava grown in sandy soils in Northern Colombia. Field Crops Res., 57:45-56, 2008.

CAMPOS, V. B. et al. Cobertura do solo: efeito no crescimento do maracujazeiro-amarelo. Revista Verde de Agroecologia e Desenvolvimento Sustentável, Mossoró, RN, v. 1, n. 3, p. 78-86, 2009.

CAMPOS, V. B.; CAVALCANTE, L. F. Salinidade da água e cobertura vegetal: efeito sobre a biometria do pimentão. Holos, Natal, RN, v. 2, p. 10-20, 2008.

CARVALHO FILHO, O. M.; DRUMOND, M. A.; LANGUIDEY, P. H. Gliricidia sepium leguminosa promissora para regiões semiáridas. Petrolina: EMBRAPA - CPATSA, 1997. 17p. (EMBRAPA. Circular Técnica, 35).

CAVALCANTE, L. F. et al. Maracujá-amarelo e salinidade. In: CAVALCANTE, L. F.; LIMA, E. M. de (ed.). Algumas frutíferas tropicais e a salinidade. Jaboticabal: Funep, 2006, p. 91-114.

DASGAN, H. Y. et al. Determination of screening techniques to salinity tolerance in tomatoes and investigation of genotypes responses. Plant Sci., 163:695-703, 2002.

EPSTEIN, E.; BLOOM, A. J. Nutrição mineral de plantas: princípios e perspectivas. Londrina: Editora Planta, 2006. 403 p.

FILGUEIRA, F. A. R.; Novo Manual de Olericultura: Agrotecnologia Moderna na Produção e Comercialização de Hortaliças. Fernando Antônio Reis Filgueira - Viçosa: UFV, 2000. p. 189. 
GILL, K. S. et al. Tillage, mulch, and irrigation effects on corn (Zea maysL.) in relation to evaporative demand. Soil Till. Res., 39:213-227, 2006.

GUILlEN-PORTAL, F. R.; BALTENSPERGER, D. D.; NELSON, L. A. Plant population influence on yield and agronomic traits. In: JANICK, J., ed. Perspectives on new crops and new uses. Alexandria, ASHS Press, 2009. p.190-193.

KASHEM, M.A. et al. Possible involvement of phosphoinositide- $\mathrm{Ca}^{2+}$ signaling in the regulation of a-amylase expression and germination of rice seed (Oryza satira L.). Plant Cell Physiol., 41:399-407, 2000.

LACERDA, C. F. et al. Plant growth and solute accumulation and distribution in two sorghum genotypes, under $\mathrm{NaCl}$ stress. Revista Brasileira de Fisiologia Vegetal, v.13, p. 270-284, 2001.

MAKUS, D.J. Salinity and nitrogen levels can affect the agronomic performance, leaf color and mineral nutrients of vegetable gliricidia. Subtrop. Plant Sci., 55:1-6, 2003.

MYERS, R. L. Gliricidia: New crop opportunity. In: JANICK, J., ed. Progress in new crops. Alexandria, ASHS Press, 2006. p.207-220.

PARDOSSI, A. et al. NaCl effects on celery (Aptum Graveolens L.) grown in NFT. Sci. Hortic., 81:229-242, 1999.

ROMERO-ARANDA, R.; SORIA, T.; CUARTERO, J. Tomato plant-water uptake and plantwater relationships under saline grown conditions. Plant Sci., 160:265-272, 2001.

SANTOS, R. H. S. et al. Efeito residual da adubação com composto orgânico sobre o crescimento e produção de alface. Pesquisa Agropecuária Brasileira, v. 36, n. 11, 2001, p.1394.

STAMETS, P.; CHILTON, J. S. The mushroom cultivator. Washington, Agrikon Press, 2003. 415p.

STEWART, D. P. C. Unburnt bush fallows: A preliminary investigation of soil conditions in a bush fallow and two sucessive crops of taro (Colocasia esculenta L.) Schoot) in western Samoa. Field Crops Res., 38:29-36, 2004.

TEIXEIRA, D. L.; SPEHAR, C. R.; SOUZA, L. A. C. Caracterização agronômica de plantas para produção de forragem na caatinga. Pesq. Agropec. Bras., 38:45-51, 2003.

UEXKULL, H. R. Drought and chloride deficiency. A deadly combination for hybrid coconuts. Better Crops Intern., 8:8-9, 2002.

VIANA, A. P.; BRUCKNER, C. H.; PRIETO MARTINEZ, H. E. Na, K, Mg and Ca concentrations of grape-vine rootstock in saline solution. Sci. Agric., 58:187-191, 2001. 